\section{Priming with a Combination of Proangiogenic Growth Factors Enhances Wound Healing in Streptozotocin-Induced Diabetes in Mice}

\author{
Maximilian Ackermann ${ }^{a}$ Tanja Wolloscheck ${ }^{a}$ Axel Wellmann ${ }^{b}$ Vincent W. Lic, d \\ William W. Li $^{\text {d }}$ Moritz A. Konerding ${ }^{a}$ \\ anstitute of Functional and Clinical Anatomy, Johannes Gutenberg University Mainz, Mainz, and \\ ${ }^{b}$ Institute of Pathology Celle, Celle, Germany; 'Angiogenesis and Wound Center, Brigham and Women's Hospital, \\ Harvard Medical School, Boston, Mass., and ${ }^{\mathrm{d}}$ The Angiogenesis Foundation, Cambridge, Mass., USA
}

\begin{tabular}{l} 
C) Free Author \\
Copy - for per- \\
sOnal use only \\
ANY DISTRIBUTION OF THIS \\
ARTICLE WITHOUT WRITTEN \\
CONSENT FROM S. KARGER \\
AG, BASEL IS A VIOLATION \\
OF THE COPYRIGHT. \\
Written permission to distrib- \\
ute the PDF will be granted \\
against payment of a per- \\
mission fee, which is based \\
on the number of accesses \\
required. Please contact \\
permission@ $@$ karger.ch \\
\hline
\end{tabular}

\section{Key Words}

bFGF · PDGF · Proangiogenic growth factors •

Streptozotocin-induced diabetes $\cdot$ VEGF • Tensile strength • Infrared thermography

\begin{abstract}
Background: Numerous proangiogenic growth factors have been shown to improve impaired wound healing. This study evaluated the effects of subcutaneous pretreatment with a combination of proangiogenic growth factors on wound closure, mechanical properties, vessel density, and morphology. Methods: Thirty-six Balb/c mice with streptozotocin-induced diabetes were divided into 3 groups. A mixture of VEGF $(35.0 \mu \mathrm{g}), \mathrm{bFGF}(2.5 \mu \mathrm{g})$, and PDGF $(3.5 \mu \mathrm{g})$ was administered subcutaneously 3,5 , and 7 days prior to wounding in the first group, whereas the second group received three doses of $3.5 \mu \mathrm{g}$ PDGF. Wound sizes were assessed daily and the repaired tissues were harvested 7 days after wound closure. Results: Complete closure ( $\geq 95 \%$ healing of initial wound area) was reached in all proangiogenic pretreated animals by day 17 , whereas the PDGF monotherapy group needed up to 20 days for complete closure. By the time of tissue harvesting on day 24 , complete closure was not
\end{abstract}

reached in all control animals. Punch biopsy material revealed 1.6-fold higher vessel densities in the proangiogenic combination-pretreated group than in the controls. Conclusions: Proangiogenic priming revealed several significant effects on diabetic wound healing: faster time to closure, a higher vessel density, and improved functional outcome.

Copyright $\odot 2011$ S. Karger AG, Basel

\section{Introduction}

Diabetes affects approximately 170 million people worldwide, and it is anticipated that this number will double in the next 20 years [1]. Diminished production of proangiogenic growth factors and decreased wound angiogenesis are thought to contribute to impaired wound repair in diabetic patients [2]. Wound healing is strongly dependent on the formation of granulation tissue, which in turn is intimately correlated with the induction of new vessel formation. Wound angiogenesis represents a merged process that relies on the extracellular matrix in the wound bed as well as on the migration and mitogenic stimulation of endothelial cells [3]. Within this process, vascular endothelial growth factor (VEGF) enhances tis-

\section{KARGER}

Fax +41613061234 E-Mail karger@karger.ch www.karger.com

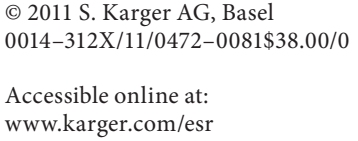

Moritz A. Konerding

Institute of Functional and Clinical Anatomy

Johannes Gutenberg University Mainz

DE-55099 Mainz (Germany)

Tel. +496131 39 22549, E-Mail konerdin@uni-mainz.de 
sue repair by stimulating proliferation in preexisting endothelial cells and increasing collagen deposition $[4,5]$, whereas fibroblast growth factor (FGF) and platelet-derived growth factor (PDGF) regulate predominantly the synthesis and deposition of extracellular protein components and additionally intensify wound angiogenesis. PDGF stimulates macrophages and boosts the secretion of other growth factors of importance in the healing process and several matrix molecules, such as fibronectin, collagen, proteoglycans, and others.

Several studies have examined whether angiogenesis stimulation can be used to promote wound healing. Adenoviral gene transfer with proangiogenic growth factors (especially VEGF) was shown to accelerate diabetic healing, whereas topical application with VEGF or PDGF showed ambivalent results [6]. Our own previous experiments [7] have shown the potential therapeutic benefits of priming angiogenesis and cell attraction prior to surgery with a combination of proangiogenic growth factors for wound healing in normoglycemic mice. Priming with a combination of supraphysiological doses of VEGF, FGF, and PDGF led to faster times to closure, higher vessel densities, and better functional outcomes [7]. A combinatory approach may therefore better mimic the complex interactions of the wound microenvironment than monotherapy using only a single factor. Furthermore, priming of skin tissue with proangiogenic growth factors could represent a potential approach for the preparation of skin flaps in plastic surgery. Giunta et al. [8] used AdVEGF 165 gene transfer 7 and 3 days prior to flap harvest and obtained a significantly increased flap survival and a higher perfusion. Preconditioning or priming with proangiogenic growth factors appears, therefore, to be a potent strategy for the enhancement of tissue repair.

The aim of the present study was to elucidate the effects of priming with a combination of proangiogenic growth factors or monotherapy with PDGF on wound healing in streptozotocin (STZ)-induced diabetic animals.

\section{Methods}

\section{Animals}

Thirty-six female Balb/c mice (25-33 g) were used for these experiments. They were obtained from the Central Animal Facilities of the University of Mainz and housed in an approved animal care facility with 12-hour light/dark cycles. Food and water were provided ad libitum. The care of the animals was consistent with legal guidelines and all experiments were conducted following approval by the local animal welfare authorities (license No. 1.5 177-07/041-2). Animals were kept in individual cages during the experiments in order to avoid biting and interference with the wounds. As long as the wounds were still open and wet, soft tissue paper was used instead of conventional bedding in order to avoid wound irritation or contamination.

\section{STZ-Induced Diabetes Model}

To assess the effects of priming on diabetic mice, hyperglycemia was induced by intraperitoneal injections [9] of $150 \mathrm{mg} / \mathrm{kg}$ body weight STZ (Sigma-Aldrich, Taufkirchen, Germany). The injection of STZ was repeated twice on every other day with a concentration of $50 \mathrm{mg} / \mathrm{kg}$ body weight. Blood glucose levels were determined weekly, and mice that did not show hyperglycemia $\geq 250 \mathrm{mg} / \mathrm{dl}$ at the time of surgery were excluded from the study.

\section{Growth Factor Priming}

The dorsal skin of the mice was shaved and depilated. Three, 5 , and 7 days prior to surgery, a combination of $35.0 \mu \mathrm{g}$ VEGF (R\&D Systems, Minneapolis, Minn., USA), $2.5 \mu \mathrm{g}$ basic FGF (bFGF; R\&D Systems), and $3.5 \mu \mathrm{g}$ PDGF (R\&D Systems) dissolved in $0.2 \mathrm{ml}$ saline solution was injected subcutaneously 1.0 $\mathrm{cm}$ paramedian in STZ-induced diabetic mice. The PDGF monotherapy group received 3.5 $\mu \mathrm{g}$ PDGF (R\&D Systems) and the control animals $0.2 \mathrm{ml}$ saline solution (B. Braun, Melsungen, Germany). This combination of different growth factors and the respective dosages were based on our own preliminary tests and on a review of the available literature.

Surgery

Mice were anesthetized with an intraperitoneal injection of avertin (1.5 ml/100 g body weight, 2,2,2-tribromoethanol; SigmaAldrich, Munich, Germany). Immediately before biopsy, an area of $15 \times 15 \mathrm{~mm}$ was shaved again using disposable shavers, followed by skin disinfection with $70 \%$ ethanol. Under sterile conditions, $8-\mathrm{mm}$ circular full-thickness punch biopsy wounds were made using disposable punches (Stiefel, Offenbach, Germany) in the midline of the lumbar dorsal skin of the mice.

\section{Wound Size Analysis}

Digital photographs (JVC KY-F75U; JVC, Yokohama, Japan) were taken at the time of surgery and daily thereafter using a working distance of $18 \mathrm{~cm}$. A marker (length $5 \mathrm{~mm}$ ) was placed on the back of the animal for reference. The wound areas were measured by tracing wound margins with a fine resolution computer stylus and were analyzed by means of morphometry software (Diskus 4.80; Hilgers, Königswinter, Germany). Wound areas (in \%) were calculated as actual residuals in reference to the wound areas on day 1 after surgery. Wound closure was defined as $\geq 95 \%$ wound closure according to the FDA guidance for industry 'Chronic Cutaneous Ulcers and Burn Wounds - Developing Products for Treatment' [10].

\section{Infrared Thermography}

To assess any possible effects of angiogenic factors on local perfusion, an infrared thermographic system (Varioscan ST3021; Jenoptik AG, Jena, Germany) was used. Thermograms were taken from non-anesthetized mice on day 22 after surgery at a distance of $12 \mathrm{~cm}$. The computerized evaluation was carried out using Irbis ${ }^{\circledR}$ control software (version 2.2; InfraTec GmbH, Dresden, Germany). Temperatures were measured in the wound bed, the wound margin, and the adjacent unwounded tissue with line and area scans. The wound itself could be easily identified due to 
the relative local hyperthermia and was confirmed by comparing the IRT image with the macroscopic appearances. A 2-mm wide rim encircling the wound bed was defined as the wound margin. Unwounded skin at a distance of at least $4 \mathrm{~mm}$ from the wound margin was used for reference measurements.

\section{Tissue Sampling and Histology}

Animals were sacrificed on day 24 after surgery. The central parts of the wound area were used for the maximum tensile strength measurements, and the adjacent parts for histology and immunochemistry. Five-micrometer thin sections of paraffinembedded specimens were stained with hematoxylin-eosin and picrosirius red according to standard protocols. Hematoxylin-eosin-stained sections were used to assess tissue layer thicknesses of the epidermis and dermis, scar thickness, and the progress of remodeling with image analyzing software Diskus 4.80 (Hilgers). All sections underwent blinded quantitation by an independent observer.

Picrosirius red staining was used to quantify the collagen content [11], which was expressed as the percentage of red-stained pixels using the image-analyzing software KS300 (Kontron AG, Eching, Germany). Areas of green (type III collagen-like) and red (type I collagen-like) were calculated for each field captured. The same settings were used for all analyses.

Immunohistochemical staining of endothelial cells was performed using a monoclonal antibody against CD31 (BD Biosciences Pharmingen, Heidelberg, Germany). Antibody binding was visualized via a 3 -step staining procedure using a biotinylated polyclonal anti rat IgG secondary antibody (DakoCytomation GmbH, Hamburg, Germany) and the streptavidin horseradish peroxidase reaction together with the DAB detection system. Vessel densities were assessed using a Weibel grid [12] and expressed as percentage of vessel surface area.

\section{Tensile Strength Measurements}

Test strips were punched out from the harvested wound vertically to the craniocaudal axis on day 24 after surgery. The test strips had an hour glass form with $3 \mathrm{~mm}$ width at the narrowest part constituting a predetermined breaking point. The design of the hour glass form was based on material testing standards. Test strips without the hour glass form would inevitably tear at the wedge grips, where the tissue is already bruised. The breaking strength testing device consisted of two opposed gripping jaws which fixed the tissue strip. The electric motor-driven gripping jaws were moved apart with a constant strain rate of $0.5 \mathrm{~mm} / \mathrm{s}$ under displacement control. Time, force, and displacement were recorded for stretching up until failure. A position encoder (WA300) was used to register the stretching distance; a force transducer (S2, maximum value $150 \mathrm{~N}$ ) was used to quantify the power applied to the tissue strip. The endpoint was the breaking strength in Newton $\left[(\mathrm{kg} \cdot \mathrm{m}) / \mathrm{s}^{2}\right]$. The resulting values were recorded by a multiple-channel PC measuring device (Spider 8; HBM, Hottinger Baldwin Messtechnik, Darmstadt, Germany) and plotted as a force-deflection curve (software: Catman 4.5; HBM). The maximum breaking strength was determined from the stressstrain curve.

\section{Statistical Analysis}

Statistical analysis was based on measurements in at least 35 different mice. The unpaired Student's t test for samples of un- equal variances was used to calculate statistical significance. Data were expressed as means $\pm \mathrm{SD}$. The significance level for the sample distribution was defined as $\mathrm{p}<0.05$.

\section{Results}

\section{Wound Closure and Gross Appearance}

The priming of wounds with proangiogenic growth factors resulted in a temporal advantage in the woundhealing process: $50 \%$ wound closure was reached on day 6.8 in the combination group versus day 8.0 in the PDGF monotherapy group and day 8.1 in the controls (fig. 1a). On day 14 after surgery, the wounds in $91 \%$ of all proangiogenic combination-primed animals were completely healed, whereas only 75\% of wounds in PDGF monotherapy animals and 33\% in control animals reached complete closure at this time (fig. 1b). Combination proangiogenic primed animals showed significantly accelerated healing between day 6 and 14 ( $p<0.028)$. Figure 2 shows the more rapid wound closure in the combination group and illustrates the circular vessel growth seen in primed animals.

\section{Vessel Density}

Vessel densities were determined both in the wounds after sacrificing the animals, as well as in the punched skin of the pretreated wound bed on the day of surgery. Assessment of local vessel expression revealed that vessel invasion accumulates in particular into the subcutis and panniculus carnosus. The harvested tissue of combination-primed animals showed a higher cell density of cells invading the dermis (fig. 3). Figure 4a illustrates that priming resulted in a significantly higher percentage of vessel densities at the time of surgery: priming yields more than 1.6-fold higher vessel surface areas in the combination-primed group versus controls (mean: 4.5 vs. $2.8 \%$ vascular surface area, $\mathrm{p}<0.01$ ). In addition to higher vessel densities, the combinatory treatment induced a mild chronic inflammatory response, mainly represented by lymphocytes, typically seen in later phases of proper, normal wound-healing processes. This might be a major cellular correlate for the improved outcome in this group.

After complete wound closure and harvesting, vessel densities were assessed separately in the wound ground, the former wound margin, and in the adjacent unwounded tissue. The differences in vessel densities had normalized by day 24 after surgery (fig. 4b). Nonetheless, the highest values were still found in pretreated animals. 
Fig. 1. Assessment of wound healing as a function of time after wound placement in diabetic mice receiving either control treatment (20 $\mu$ l isotonic saline solution; -), combinatory proangiogenic treatment (35.0 $\mu \mathrm{g}$ VEGF, $2.5 \mu \mathrm{g}$ bFGF, and $3.5 \mu \mathrm{g}$ PDGF; $)$ ), or PDGF monotherapy (3.5 $\mu$ g; $\Delta$ ) on days 3, 5, and 7 prior to surgery. a Remaining relative wound surface. b Percentage of animals with complete wound closure ( $\geq 95 \%$ ).
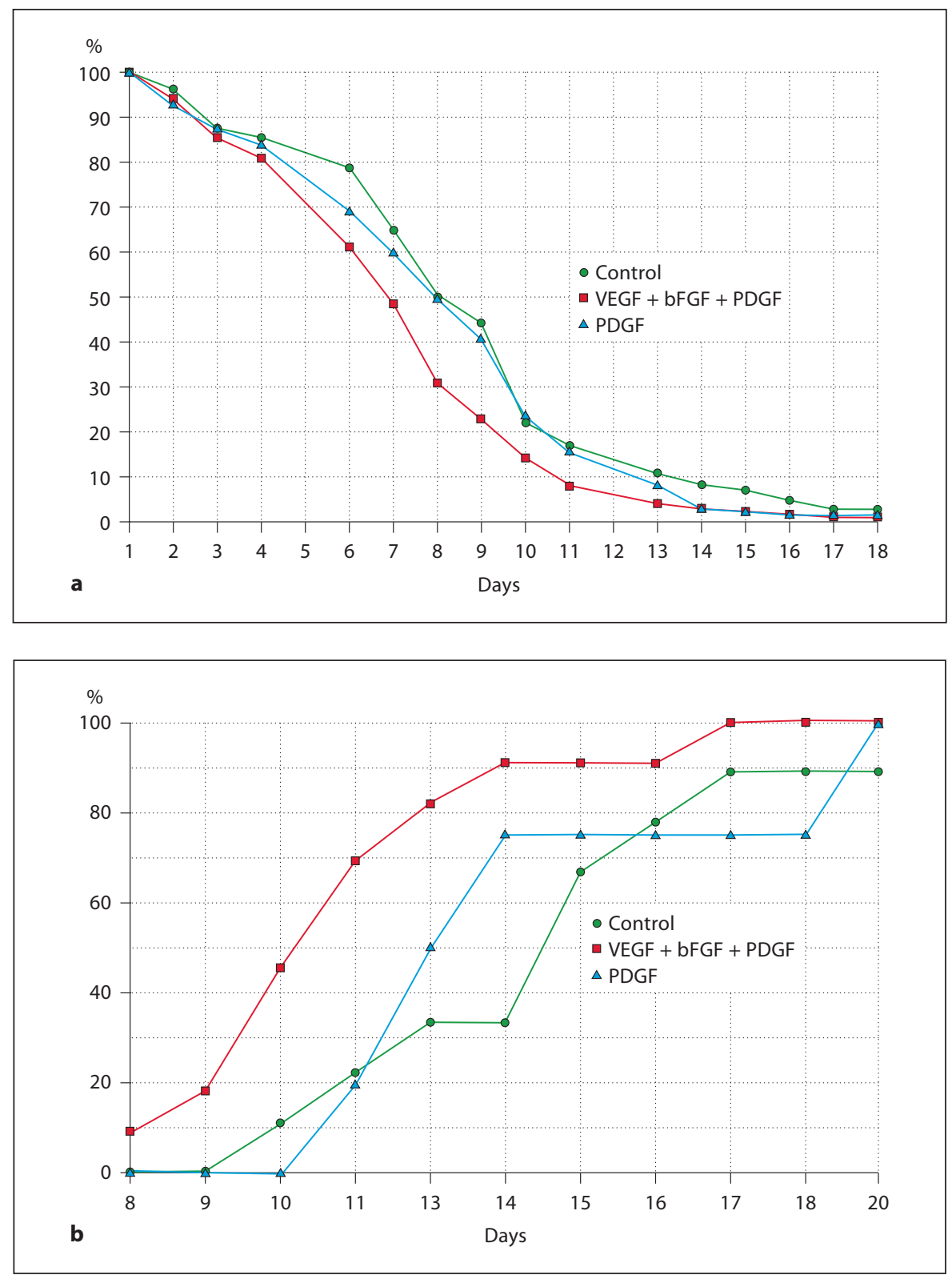

\section{Infrared Thermography}

The mean temperatures were significantly higher in the wounds of proangiogenic combination-primed mice than in controls $(\mathrm{p}<0.01)$ or in the PDGF monotherapy group $(\mathrm{p}=0.12$; fig. 5). The wound margins of the proangiogenic combination-primed animals revealed the highest temperature levels. Here, in the wound bed the mean temperature of the combination group was $0.6^{\circ} \mathrm{C}$ higher than in the control group $(p=0.05)$. In the adjacent vicinity of the wound margin the temperature in the combination group was $0.52^{\circ} \mathrm{C}$ higher than in the controls $(\mathrm{p}<0.001)$.

\section{Maximum Tensile Strength}

Functional tensile strength testing revealed a certain advantage of the proangiogenic growth factor pretreatment in comparison to the sham-treated control group, although these differences did not reach significance (fig. 6). The mean value for the combination-primed animals was $1.2 \pm 0.25 \mathrm{~N}$. The PDGF monotherapy group showed the highest variability $(1.1 \pm 0.66 \mathrm{~N})$, with a mean value of $1.0 \pm 0.3 \mathrm{~N}$ being found in the control animals. 

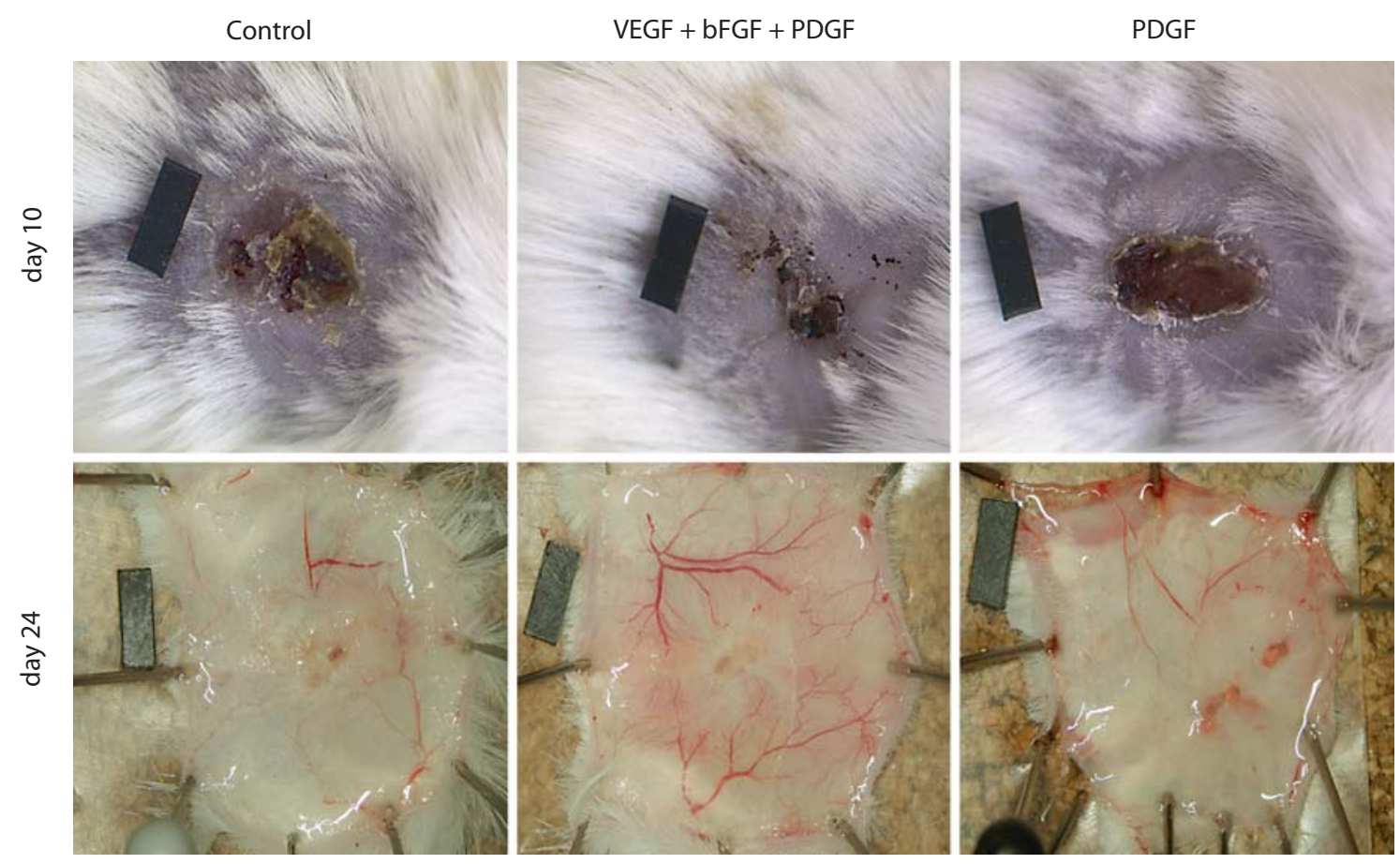

Fig. 2. Macroscopic assessment of wound closure on day 10 (upper panel) and day 24 (lower panel, back side of specimen biopsy) in representative mice receiving either control treatment $(0.2 \mathrm{ml}$ isotonic saline solution), combinatory proangiogenic treatment (35.0 $\mu \mathrm{g}$ VEGF, $2.5 \mu \mathrm{g}$ bFGF, and $3.5 \mu \mathrm{g}$ PDGF), or PDGF monotherapy $(3.5 \mu \mathrm{g})$. The black marker has a length of $5 \mathrm{~mm}$.

\section{Collagen Contents}

Figure 7 shows significant increases in the percentage of juvenile type III collagen-like fibers after surgery and PDGF monotherapy. Postoperatively, the PDGF monotherapy animals showed significantly higher values than the controls $(\mathrm{p}=0.045)$ and the proangiogenic combination-primed animals $(\mathrm{p}=0.045)$. The levels of type I collagen-like fibers showed no significant change.

\section{Discussion}

The present results show that priming with a combination of proangiogenic growth factors enhances healing as defined by faster wound re-epithelialization, higher wound vascularization, higher wound temperature, and a higher amount of juvenile collagen fiber bundles. In particular, assessment of time to closure and functional outcome revealed an advantage for the groups primed with proangiogenic growth factors in comparison to control animals. In addition, a higher degree of wound contraction was observed immediately after wounding in the groups primed with proangiogenic growth factors. Healing by contraction is more predominant than epithelialization in 'loose-skin' animals, such as the mouse, and depends on vascularization, which is elevated in groups primed with proangiogenic growth factors and which correlates with myofibroblast activity.

These results were obtained in animals with STZ-induced diabetes, which is based on a selective destruction of the pancreatic $\beta$ cells [9]. Contrary to Lepr ${ }^{d b / d b}$ knockout mice or NOD mice, STZ-induced diabetes may be regarded primarily as a model for type I diabetes. The vascular complications and the endothelial dysfunction are, however, comparable [13]. Galiano et al. [2] were able to show that STZ-induced diabetes causes a similarly decelerated wound closure to that seen in $d b / d b$ mice.

Several proangiogenic growth factors have been tested for their ability to enhance wound healing. Although many factors have demonstrated positive results on tissue repair, only PDGF (becaplermin) is available as an FDAapproved topical wound ointment $[6,14]$. Admittedly, response rates of becaplermin range at best to a modest level of $30 \%$ [14]. Topical treatment with VEGF or bFGF did 

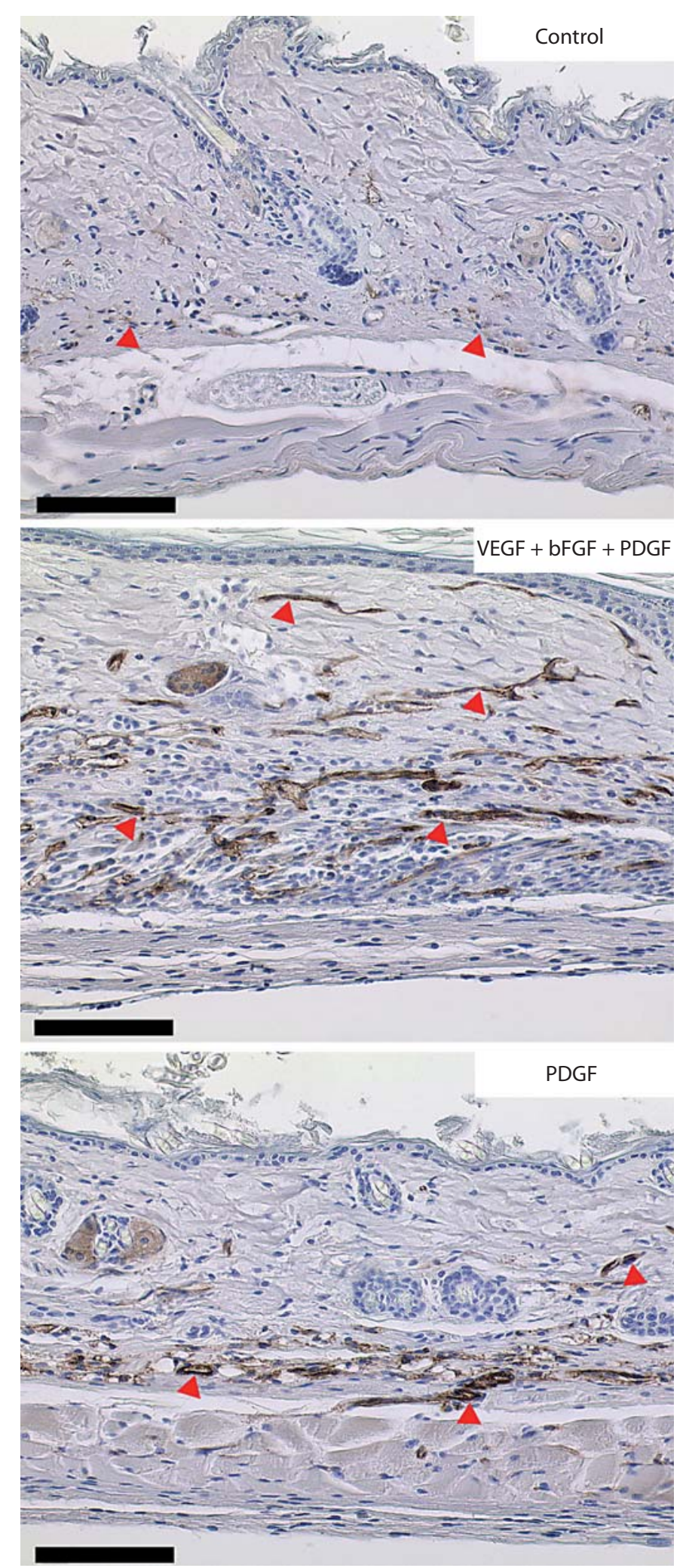

not show convincing results either $[15,16]$. This lack of efficacy may be due to a proteloytic degradation of the topically administered growth factors at the wound site. However, priming and gene therapeutic approaches are attaining more sustainable results than those obtained with topical delivery of proangiogenic growth factors: wounds require an excellent vascularization and a healthy bed of granulation tissue as a prerequisite for effective healing [14]. The crucial point of wound closure and wound re-epithelialization is the directed migration of keratinocytes towards the wound bed. This migration capacity is compromised in chronic non-healing wounds [17]. Brem et al. [18] demonstrated that the sustained release of VEGF and a distinct wound angiogenesis promote the migration of keratinocytes and wound closure. Our results for wound closure and higher vessel densities likewise confirm these findings. Furthermore, the translocation of preexisting vasculature is responsible for the rapid formation of granulation tissue [19].

We opted for a combination of VEGF, bFGF, and PDGF in comparison with PDGF alone and controls for various reasons: PDGF may be regarded as a gold standard due to FDA approval of the treatment of neuropathic ulcers. VEGF and bFGF in combination with PDGF showed convincing results in a previous study on wound healing in normoglycemic animals [7]. VEGF alone may increase the vessel density, whereas bFGF impacts not only vessel density but also vascular permeability and cell proliferation in general. A combination was thus more promising than individual growth factors.

The dosages used in this experiment were well above physiologic values. In a previous study with normoglycemic mice, we showed that these dosages may speed up wound healing and increase vessel densities prior to surgery [7], whereas physiologic dosages do not have an impact in normal mice [20]. It might well be that an improvement of wound tissue levels of angiogenic factors in diabetic animals to their physiological levels in non-diabetic animals achieves already significant improvements.

Fig. 3. Vascularization of excised punch biopsies from control animals ( $0.2 \mathrm{ml}$ isotonic saline solution; top), combinatory proangiogenic treatment (35.0 $\mu \mathrm{g}$ VEGF, $2.5 \mu \mathrm{g}$ bFGF, and $3.5 \mu \mathrm{g}$ PDGF; middle), and PDGF monotherapy ( $3.5 \mu \mathrm{g}$; bottom). Note the higher vessel density and cell invasion in the proangiogenic combination-primed animals. In addition to higher vessel density, the combination of three growth factors induces a mild chronic inflammatory response as typically seen in later phases of normal wound-healing processes. 

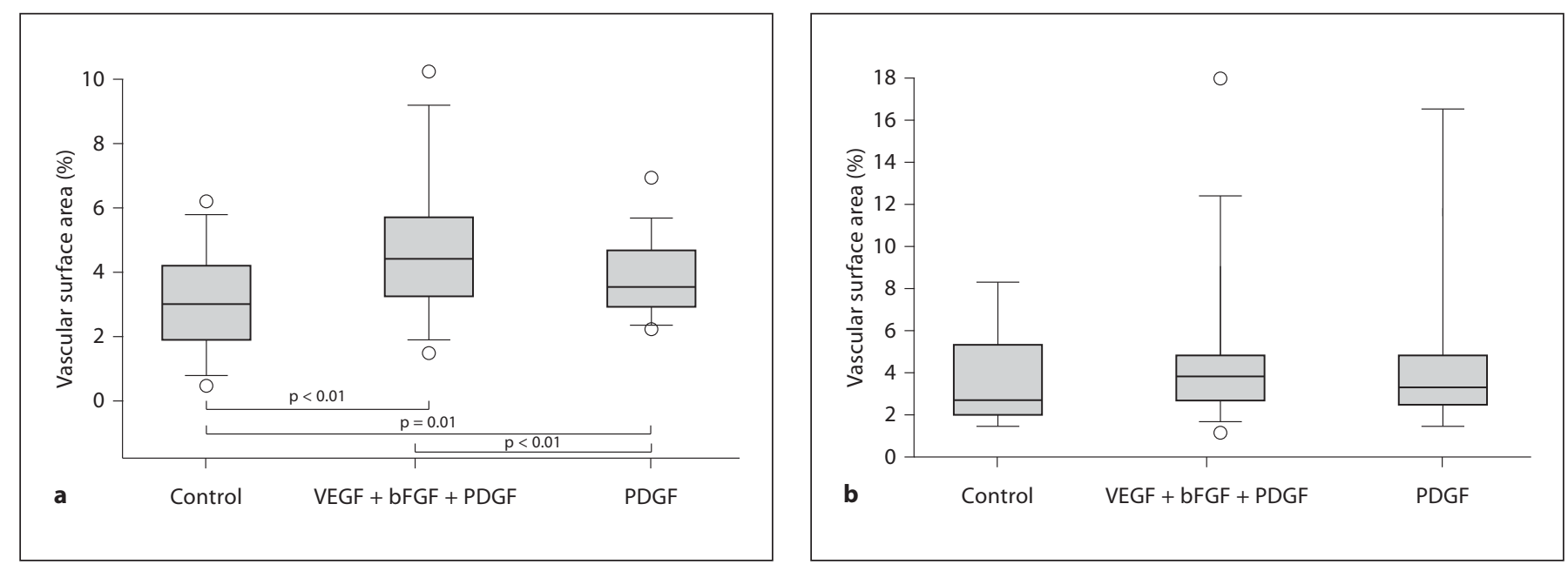

Fig. 4. Microvessel densities of harvested wound tissue in controls ( $0.2 \mathrm{ml}$ isotonic saline solution), combinatory proangiogenic treatment (35.0 $\mu \mathrm{g}$ VEGF, $2.5 \mu \mathrm{g}$ bFGF, and $3.5 \mu \mathrm{g}$ PDGF), and PDGF monotherapy (3.5 $\mu \mathrm{g}$ ) on the day of surgery (day 0; a) and on day 24 (b) after wounding, assessed using anti-CD31 staining. Boxwhisker plots showing the median, 5th, 10th, 25th, 75th, 90th, and 95th percentiles.

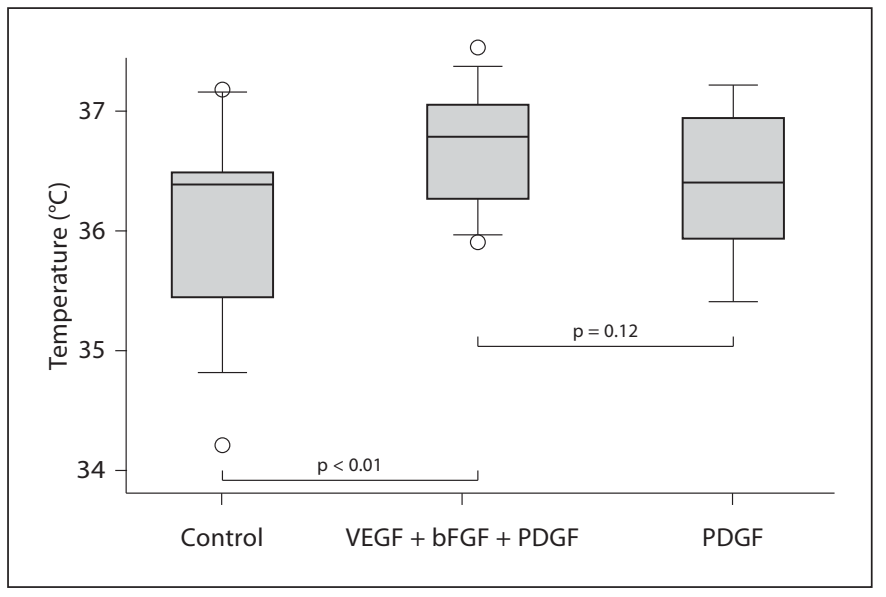

Fig. 5. Infrared thermography of full-thickness biopsy wounds indicating that the temperature levels in the wound bed are significantly higher in the pretreated animal groups. Box-whisker plots showing the median, 5th, 10th, 25th, 75th, 90th, and 95th percentiles.

The vasculature of granulation tissue is characterized by a greater number of widely enlarged capillaries $[19,21]$. The various mechanisms of vessel growth play a pivotal role during wound healing: intussusceptive angiogenesis has been shown to occur during wound healing. Vascular intussusception is characterized by intraluminal invaginations caused by endothelial cells or cells of connective

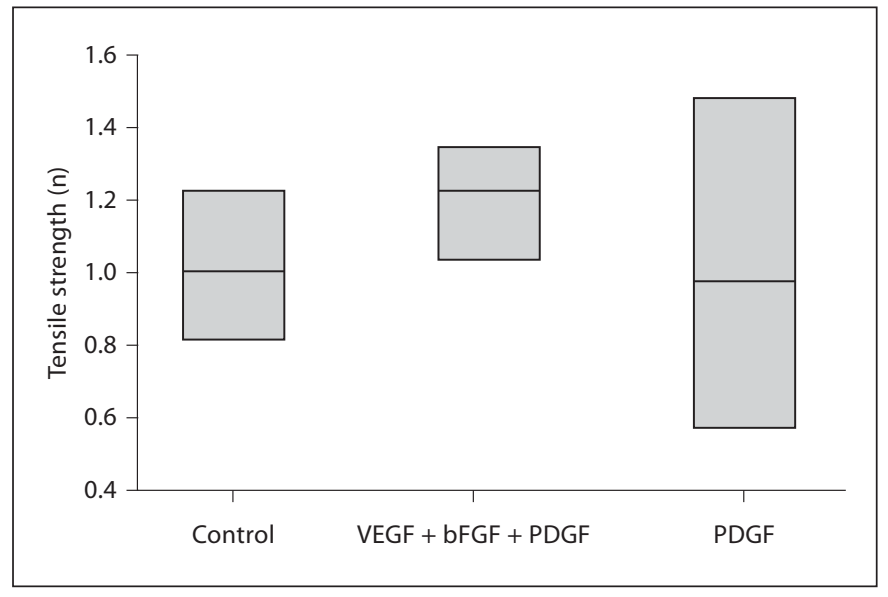

Fig. 6. Comparison of tensile strength values obtained on day 24 after surgery. Mice received either control treatment $(0.2 \mathrm{ml}$ isotonic saline solution), combinatory proangiogenic treatment (35.0 $\mu \mathrm{g}$ VEGF, $2.5 \mu \mathrm{g}$ bFGF, and 3.5 $\mu \mathrm{g}$ PDGF), or PDGF monotherapy $(3.5 \mu \mathrm{g})$ on days 3, 5 and 7 prior to surgery. Box-whisker plots showing the median, 10th, 25th, 75th, and 90th percentiles.

tissue [21]. One important characteristic of intussusceptive vascular growth is that it can be achieved at an extremely low rate of endothelial cell proliferation [22]. Buds are functional vessels that are constantly perfused with blood. Our results suggest that proangiogenic combination priming facilitates the early stages of wound healing. In this study, we have been able to demonstrate 


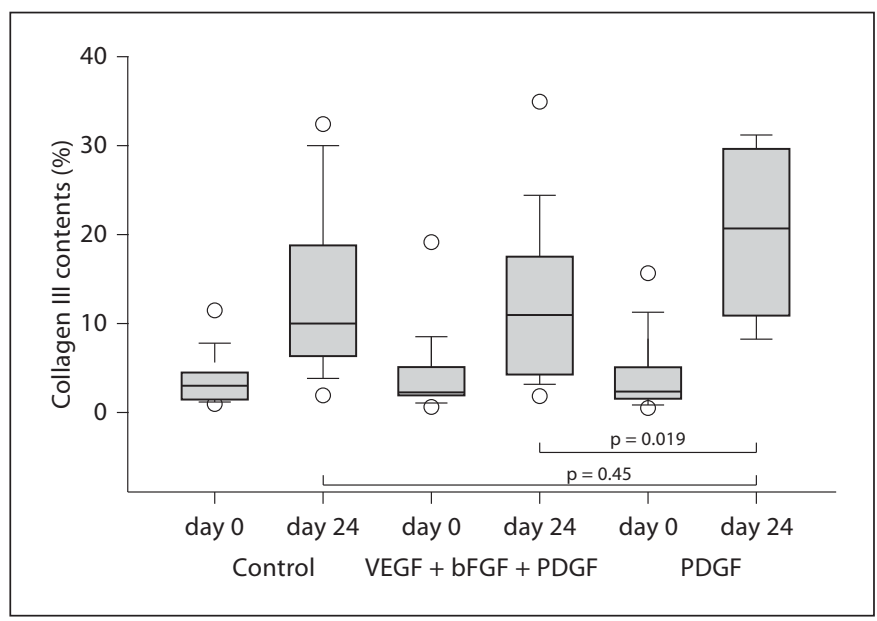

Fig. 7. Assessment of juvenile type III collagen-like fibers on day 0 and 24 after wounding using picrosirius red staining. Mice received either control treatment $(20 \mu \mathrm{l}$ isotonic saline solution), combinatory proangiogenic priming $(35.0 \mu \mathrm{g}$ VEGF, $2.5 \mu \mathrm{g}$ bFGF, and $3.5 \mu \mathrm{g}$ PDGF), or PDGF monotherapy (3.5 $\mu \mathrm{g})$. PDGF monotherapy animals showed a significant increase in collagen III contents on day 24 after surgery. Box-whisker plots showing the median, 5th, 10th, 25th, 75th, 90th, and 95th percentiles.

that the priming of preexisting host vasculature leads to a higher vessel density in the wound bed at the time of surgery. A prominent vasculature at the time of surgery initiates a strong angiogenic response that is accompanied by vascular leakage, fibrin deposition, and the beginning of the inflammatory phase [23] in granulation tissue. Vessel densities on day 24 after surgery, in contrast, showed no significant advantage over those seen in primed animals. In our own experiments in normoglycemic mice, significantly higher vessel densities were found in primed animals on the day of surgery and on day 17 after surgery. Numerous studies have indicated that vascular regression is probably a regulated process in wound healing, with endothelial cells undergoing apoptosis [24, 25]. Different matrix metalloproteinases and plasminogen have been shown to induce vascular regression during the formation of highly vascularized granulation tissue [25], and a long-lasting period of angiogenesis has been observed to comprise of the remodeling phase and maturation of wounds [26, 27]. Therefore, proangiogenic priming mimics the physiological continuum of vessel induction and vessel regression, which is in contrast to the permanent angiogenic stimuli occurring during topical treatment.

Infrared thermography was used for non-invasive monitoring of temperature as a surrogate marker of local tissue perfusion. The thermal resolution of infrared thermography is usually better than $0.1 \mathrm{~K}$ so that thermograms can be used to detect minimal heterogeneities in tissue temperature. In the present study, higher temperatures were found in the wound bed, wound margin, and adjacent tissue in the animals primed with proangiogenic growth factors. The influence of vasoregulation on blood flow in remodeled tissue should be considered as a crucial element in the control of perfusion. Nonetheless, the stimulation of vascularization through application of proangiogenic growth factors is also thought to be capable of significantly increasing local tissue perfusion [2729].

Collagen synthesis and deposition are crucial for wound closure and the development of wound tensile stiffness. VEGF, FGF, and PDGF have been shown to stimulate fibroblast migration and enhance collagen deposition $[28,29]$. In our study, collagen deposition following application of proangiogenic growth factors was seen to change towards a higher level of juvenile type III collagen-like fibers, suggesting intensified tissue remodeling by vascularized tissue, similar to that seen in granulation tissue [30, 31]. Considering the results obtained, there does not appear to be a stringent correlation between collagen content and tensile stiffness. This may be due to the early harvesting of scar tissue on day 24 . Remodeling and scar maturation seem not to be completed by day 24 after surgery, whereas our own wound healing studies on combinatory proangiogenic priming in normoglycemic mice revealed an almost 2 -fold higher breaking strength in primed animals on day 17 . These data suggest that the combinatory proangiogenic growth factor approach has more than an additive effect on the deposition and arrangement of collagen bundles. Wound vascularization seems to be a relevant prerequisite for collagen deposition and cross-linking. Furthermore, numerous extracellular proteins, e.g. fibronectin and tenascin, can be seen as a pivotal criterion influencing collagen crosslinking and wound angiogenesis [31]. The newly forming blood vessels deposit a provisional matrix of fibronectin and proteoglycans $[32,33]$.

Taken together, these results show that combinatory proangiogenic priming with VEGF, bFGF, and PDGF results in faster wound closure, higher vessel density, and a better functional outcome. Priming has now revealed accelerated healing in both normoglycemic and diabetic mice. Future experiments are planned which will examine the effects of the individual proangiogenic growth factors and compare the effects of proangiogenic priming with gene therapeutic approaches. 


\section{Acknowledgments}

This work was supported by grants from the German Army to M.A.K. and A.W. (M-SAB 1-5-A009) and The Angiogenesis Foundation. The authors acknowledge the skillful technical assistance of Kerstin Bahr and thank Dr. Bickes-Kelleher for the critical review of the manuscript.

\section{Disclosure Statement}

The authors state no conflict of interest.

\section{References}

1 Brem H, Tomic-Canic M: Cellular and molecular basis of wound healing in diabetes. J Clin Invest 2007;117:1219-1222.

2 Galiano RD, Tepper OM, Pelo CR, Bhatt KA, Callaghan M, Bastidas N, Bunting S, Steinmetz HG, Gurtner GC: Topical vascular endothelial growth factor accelerates diabetic wound healing through increased angiogenesis and by mobilizing and recruiting bone marrow-derived cells. Am J Pathol 2004;164: 1935-1947.

3 Singer AJ, Clark RA: Cutaneous wound healing. N Engl J Med 1999;341:738-746.

4 Risau W: Mechanisms of angiogenesis. Nature 1997;386:671-674

5 Witte MB, Kiyama T, Barbul A: Nitric oxide enhances experimental wound healing in diabetes. Br J Surg 2002;89:1594-1601.

6 Chan RK, Liu PH, Pietramaggiori G, Ibrahim SI, Hechtman HB, Orgill DP: Effect of recombinant platelet-derived growth factor (Regranex) on wound closure in genetically diabetic mice. J Burn Care Res 2006;27:202205.

7 Ackermann M, Wolloscheck T, Wellmann A, Li VW, Li WW, Konerding MA: Priming with a combination of proangiogenic growth factors improves wound healing in normoglycemic mice. Int J Mol Med 2011;27:647653

8 Giunta RE, Holzbach T, Taskov C, Holm PS, Konerding MA, Schams D, Biemer E, Gänsbacher B: AdVEGF165 gene transfer increases survival in overdimensioned skin flaps. J Gene Med 2005;7:297-306.

9 Lenzen S: The mechanisms of alloxan- and streptozotocin-induced diabetes. Diabetologia $2008 ; 51: 216-226$.

10 FDA Wound Healing Clinical Focus Group: Guidance for industry: chronic cutaneous ulcer and burn wounds - developing products for treatment. Wound Repair Regen 2001;9:258-268.

11 Junqueira LC, Bignolas G, Brentani RR: Picrosirius staining plus polarization microscopy, a specific method for collagen detection in tissue sections. Histochem J 1979;11: $447-455$.
12 Weibel ER, Kistler GS, Scherle WF: Practical stereological methods for morphometric cytology. J Cell Biol 1966;30:23-38.

13 Keswani SG, Katz AB, Lim FY, Zoltick P, Radu A, Alaee D, Herlyn M, Crombleholme TM: Adenoviral mediated gene transfer of PDGF-B enhances wound healing in type I and type II diabetic wounds. Wound Repair Regen 2004;12:497-504.

14 Bauer SM, Bauer RJ, Velazquez OC: Angiogenesis, vasculogenesis, and induction of healing in chronic wounds. Vasc Endovascular Surg 2005;39:293-306.

15 Hanft JR, Pollak RA, Barbul A, van Gils C, Kwon PS, Gray SM, Lynch CJ, Semba CP, Breen TJ: Phase I trial on the safety of topical rhVEGF on chronic neuropathic diabetic foot ulcers. J Wound Care 2008;17:30-32, 34-37.

16 Richard JL, Parer-Richard C, Daures JP, Clouet S, Vannereau D, Bringer J, Rodier M, Jacob C, Comte-Bardonnet M: Effect of topical basic fibroblast growth factor on the healing of chronic diabetic neuropathic ulcer of the foot. A pilot, randomized, doubleblind, placebo-controlled study. Diabetes Care 1995;18:64-69.

17 Raja, Sivamani K, Garcia MS, Isseroff RR: Wound re-epithelialization: modulating keratinocyte migration in wound healing. Front Biosci 2007;12:2849-2868.

18 Brem H, Kodra A, Golinko MS, Entero H, Stojadinovic O, Wang VM, Sheahan CM, Weinberg AD, Woo SL, Ehrlich HP, TomicCanic M: Mechanism of sustained release of vascular endothelial growth factor in accelerating experimental diabetic healing. J Invest Dermatol 2009;129:2275-2287.

19 Kilarski WW, Samolov B, Petersson L, Kvanta A, Gerwins P: Biomechanical regulation of blood vessel growth during tissue vascularization. Nat Med 2009;15:657-664.

20 Corral CJ, Siddiqui A, Wu L, Farrell CL, Lyons D, Mustoe TA: Vascular endothelial growth factor is more important than basic fibroblastic growth factor during ischemic wound healing. Arch Surg 1999;134:200205.
21 Dudar TE, Jain RK: Microcirculatory flow changes during tissue growth. Microvasc Res 1983;25:1-21.

22 Hashimoto H, Prewitt RL: Microvascular density changes during wound-healing. Int J Microcirc Clin Exp 1987;5:303-310.

23 Kilarski WW, Gerwins P: A new mechanism of blood vessel growth - hope for new treatment strategies. Discov Med 2009;8:23-27.

24 Ausprunk DH, Folkman J: Migration and proliferation of endothelial cells in preformed and newly formed blood vessels during tumor angiogenesis. Microvasc Res 1977; 14:53-65.

25 Brown NJ, Smyth EA, Cross SS, Reed MW: Angiogenesis induction and regression in human surgical wounds. Wound Repair Regen 2002;10:245-251.

26 Greenhalgh DG: The role of apoptosis in wound healing. Int J Biochem Cell Biol 1998; 30:1019-1030.

27 Arroyo AG, Iruela-Arispe ML: Extracellular matrix, inflammation, and the angiogenic response. Cardiovasc Res 2010;86:226-235.

28 Endrich B, Menger MD: Regeneration der Mikrozirkulation während der Wundheilung? Unfallchirurg 2000 Nov;103:10061018.

29 Semenza GL: Regulation of tissue perfusion in mammals by hypoxia-inducible factor 1 . Exp Physiol 2007;92:988-991.

30 Bao P, Kodra A, Tomic-Canic M, Golinko MS, Ehrlich HP, Brem H: The role of vascular endothelial growth factor in wound healing. J Surg Res 2009; 153:347-358.

31 Barrientos S, Stojadinovic O, Golinko MS, Brem H, Tomic-Canic M: Growth factors and cytokines in wound healing. Wound Repair Regen 2008;16:585-601.

32 Li J, Zhang YP, Kirsner RS: Angiogenesis in wound repair: angiogenic growth factors and the extracellular matrix. Microsc Res Tech 2003;60:107-114.

33 Tonnesen MG, Feng X, Clark RA: Angiogenesis in wound healing. J Investig Dermatol Symp Proc 2000;5:40-46.

\section{(C) Free Author Copy - for personal use only}

ANY DISTRIBUTION OF THIS ARTICLE WITHOUT WRITTEN CONSENT FROM S. KARGER AG, BASEL IS A VIOLATION OF THE COPYRIGHT.

Written permission to distribute the PDF will be granted against payment of a permission fee, which is based on the number of accesses required. Please contact permission@karger.ch 